$(c)$ EY

\title{
PRÁTICAS EDUCATIVAS DE PROFESSORES DE EDUCAÇÃO FÍSICA DO ENSINO FUNDAMENTAL E SUA RELAÇÃO COM A TEORIA DOS ESTILOS PARENTAIS
}

\begin{tabular}{c}
\hline EDUCATIONAL PRACTICES OF ELEMENTARY \\
SCHOOL PHYSICAL EDUCATION TEACHERS AND \\
ITS RELATION WITH THE \\
PARENTAL STYLES THEORY \\
\hline PRÁCTICAS EDUCATIVAS DE PROFESSORES \\
DE EDUCACIÓN FÍSICA DE LA ENSENANZA PRIMARIA \\
Y SUS RELACIONES CON LA \\
TEORIA DE LOS ESTILOS PARENTALES
\end{tabular}

\author{
Aline Santos Souza ${ }^{1}$ \\ Arnaldo Leitão ${ }^{1}$, \\ Elaine Prodócimo ${ }^{1}$
}

\begin{abstract}
RESUMO
O presente estudo teve como objetivo analisar as posturas de professores de Educação Física do Ensino Fundamental Segundo Ciclo, a partir da tipologia da Teoria dos Estilos Parentais, propostas por Baumrind (1966). Buscou-se também analisar as possíveis influências das posturas dos professores sobre o clima afetivo das aulas de Educação Física. Para isso, foram observadas aulas de professores da rede pública de ensino de Campinas, registradas em diário de campo. Para organização e análise dos dados, utilizou-se uma adaptação do Questionário de Estilos e Dimensões Parentais (QEDP) - Versão Reduzida, que serviu como base para a relação entre os estilos parentais e a forma de atuação docente. Como resultado, foi percebida a predominância de condutas permissivas e a pouca autoridade dos docentes sobre seus alunos. Concluiu-se que os professores adotam posturas permissivas para evitar conflitos, o que torna suas aulas esvaziadas de conteúdo.
\end{abstract}

PALAVRAS-CHAVE: Estilos parentais. Educação física escolar. Autoridade.

\begin{abstract}
This study aimed to analyze the postures of elementary school Physical Education teachers, from the typology of the Parental Styles Theory proposed by Baumrind (1966). It also sought to analyze the possible influences of teachers' attitudes about the emotional climate of the Physical Education classes. For this, classes of teachers from Campinas public school network were observed and registered on a field journal. For organization and data analysis, we used an adaptation of Styles and Parental Dimensions Questionnaire (QEDP) - Reduced version, which was the basis for the relationship between parenting styles and the teaching performance ways. As a result it was perceived the prevalence of permissive behavior and the little authority of teachers on their students. It was concluded that teachers adopt permissive attitudes to avoid conflicts, which makes their classes emptied of content.
\end{abstract}

KEYWORDS: Parental styles. School physical education. Authority.

\footnotetext{
${ }^{1}$ Universidade Estadual de Campinas - UNICAMP, Campinas, São Paulo - Brasil

Contato: line.nin92@gmail.com

Submetido em: 26 set. 2015 - Aceito em: 16 fev. 2016

\begin{tabular}{|l|l|l|l|l|l|l}
\hline CCConexões & Campinas, SP & v. 14 & n. 1 & p. 66-86 & jan./mar. 2016 & ISSN 1983-9030 \\
\hline
\end{tabular}
}




\section{RESUMEN}

El objetivo del presente trabajo ha sido analizar las posturas de profesores de Educación Física de la enseñanza primaria y secundaria, desde la tipologia de la Teoría de los Estilos Parentales, propuesta por Baumrind (1966), y también analizar las posibles influencias de estas posturas sobre el clima afectivo en sus clases. Se observó y se registró en diarios de campo, clases de profesores de la red pública de de Campinas, SP, Brasil. Los datos obtenidos fueron organizados y analizados por medio de adaptación del Cuestionario de Estilos y Dimensiones Parentales (QEDP) - Versión Reducida. El cuestionario sirvió de base para la relación entre los estilos parentales y la manera de actuación docente. Los resultados demostraron el predominio de conductas permisivas y poca autoridad de los profesores sobre sus alumnos. Se concluyó que los profesores adoptan posturas permisivas para evitar conflictos, dejando las clases, muchas veces, sin contenido.

PALABRAS CLAVE: Estilos parentales. Educación física escolar. Autoridad.

\begin{tabular}{l|l|l|l|l|l|l}
\hline (C) Conexões & Campinas, SP & v. 14 & n. 1 & p. 66-86 & jan./mar. 2016 & ISSN 1983-9030
\end{tabular}




\section{INTRODUÇÃO}

As relações interpessoais e as vivências diárias permitem que os sujeitos construam seus modos de ser e suas percepções sensíveis às estruturas normativas da sociedade (valores morais, normas e regras). As interações sociais influenciam o repertório comportamental do indivíduo, fazendo com que este desenvolva habilidades para lidar com sentimentos, adversidades e diferenças. Família e escola se configuram como primeiras fontes de socialização dos comportamentos relacionais das crianças pequenas. Ambos ambientes são dinâmicos e estão em constantes trocas socioculturais com a sociedade, recebem suas influências, mas também enviam suas demandas, pois formam indivíduos que a comporão. ${ }^{1}$

Assim como os pais, os professores também exercem papel importante na formação de indivíduos. A eles é designada socialmente a tarefa de ensinar conhecimentos especializados, além de "transmitir, consciente ou inconscientemente, valores, normas, maneiras de pensar e padrões de comportamento que contribuem eficazmente para a permanência na vida social". $2: 58$ Essa tarefa, quando permeada por relações afetivas, equilibradas e consistentes, gera um ambiente mais confortável para alunos e professores, o que facilita o processo de ensino-aprendizado. Na disciplina de Educação Física escolar, o papel do professor não é diferente: cabe a ele não só apresentar conhecimentos, mas também estimular em seus alunos experimentações, interpretações e descobertas das diferentes expressões do movimento humano.

As práticas pedagógicas da Educação Física na escola, porém, não estão desconectadas dos ambientes socioculturais. Sabe-se que o professor está inserido numa sociedade e que sofre as influências do contexto em que vive. Dessa maneira, Kunz ${ }^{3: 25}$ afirma que a Educação Física escolar já foi considerada, numa concepção mais racionalista e esportivista, uma disciplina essencialmente prática, na qual "os movimentos realizados se reduzem a ações regulamentadas e padronizadas que se orientam em grandezas mensuráveis e abstratas", por meio de práticas impostas, desconsiderando as possibilidades de reflexão por parte dos alunos.

Atualmente, observa-se que, as práticas tradicionais da Educação Física escolar esportivista foram, em parte, substituídas por um esvaziamento das intencionalidades pedagógicas, e são 
caracterizadas pelas práticas nas quais não há intervenção do professor, em que os alunos estão livres para fazerem o que quiserem, sem conteúdo ou planejamento das aulas. Para Charlot, ${ }^{4}$ tanto as práticas tradicionais, quanto aquelas em que não há intervenção do professor, podem reforçar modelos de condutas dos alunos que não estejam relacionados às finalidades pedagógicas da educação.

Nesse contexto, o presente estudo buscou analisar as posturas de professores de Educação Física do Ensino Fundamental Segundo Ciclo, a partir da tipologia da Teoria dos Estilos Parentais, propostas por Baumrind. ${ }^{5}$ Buscou-se também analisar as possíveis influências das posturas dos professores sobre o clima afetivo das aulas de Educação Física. Analisando as vertentes de práticas docentes descritas e relacionando-as aos estilos parentais, tornou-se possível supor que o professor que adota o modelo Educação Física escolar de imposição das atividades assume uma postura mais autoritária, pois exige o cumprimento de certos padrões de movimento descritos em seu plano de aula, atentando apenas para a execução e o rendimento do movimento, não oferecendo aos alunos espaço e possibilidades de reflexão e crítica sobre as práticas. Quanto ao professor que segue o modelo da não intervenção direta, entende-se que ele adota uma postura permissiva, pois não se compromete com o conteúdo das aulas ou o desenvolvimento do aluno.

\section{RELAÇÕES DE PODER E AUTORIDADE}

As relações humanas são estabelecidas pelos vínculos entre os sujeitos, mas também pelas formas de poder instituídas na sociedade. Uma relação de autoridade, por exemplo, entre pais e filhos ou professor e aluno, pode expressar sentimentos e emoções de confiança e cuidado, mas também pode resultar em imposições nem sempre percebidas pelos atores sociais. ${ }^{6}$ Essa ambiguidade entre autoridade e poder precisa ser analisada nas suas diferentes manifestações. Nesta pesquisa, focalizamos as posturas dos professores de Educação Física e suas relações com as práticas parentais, que envolvem relações de poder/autoridade.

Para Bourdieu, ${ }^{7}$ a análise das relações de poder na família e escola passa pela compreensão das posições sociais instituídas na sociedade. Segundo as pesquisas realizadas por esse sociólogo, os modos como cada sujeito se posiciona no espaço social é pré-determinado pelas origens e funções socais de cada agente. No ambiente escolar, o professor recebe uma autoridade legitimada pela valorização do acúmulo de conhecimento na sua trajetória

\begin{tabular}{l|l|l|l|l|l|l}
\hline () Conexões & Campinas, SP & v. 14 & n. 1 & p. 66-86 & jan./mar. 2016 & ISSN 1983-9030
\end{tabular}


acadêmica. Assim, o estabelecimento da autoridade está intimamente relacionado com as manifestações de poder da sociedade.

Mas, o que seria autoridade? Esse conceito não se restringe apenas à posição de quem manda, mas também daquele que exerce influências, que emana segurança e coesão em suas ações. Arendt $^{8}$ destaca ainda a importância do "ser professor", que vai muito além do acúmulo de conhecimento e da posição que ocupa: está muito mais relacionada à consciência que o professor possui da responsabilidade social de sua função e, a partir dela, à forma como desenvolve suas condutas. Quanto mais aprofundada essa consciência, mais fundada estará sua autoridade.

\begin{abstract}
A autoridade do educador e as competências do professor não são a mesma coisa. Ainda que não haja autoridade sem uma certa competência, esta, por mais elevada que seja, não poderá jamais, por si só, engendrar a autoridade. A competência do professor consiste em conhecer o mundo e em ser capaz de transmitir esse conhecimento aos outros. Mas a sua autoridade funda-se no seu papel de responsável pelo mundo. Face à criança, é um pouco como se ele fosse um representante dos habitantes adultos do mundo que lhe apontaria as coisas dizendo: "Eis aqui o nosso mundo!" $8: 239$
\end{abstract}

Nesse sentido, os educadores devem assumir posições de autoridade, sem incorrer no erro de exercê-la de forma impositiva e repressiva, homogeneizando ao invés de diversificar, o que seria uma forma de autoritarismo. De acordo com Arendt, ${ }^{9}$ o que destrói uma autoridade é a perda do seu poder efetivado, legitimado. Essa legitimação se dá pela coerência entre palavras e atos, intenções e realidades. O autoritarismo, então, seria ocupar uma posição de autoridade sem sua legitimação, utilizando-se do poder inerente à posição (e não o poder da influência) para estabelecer-se.

Com isso, a autoridade é uma relação de poder que institui contextos de confiança e segurança necessários para as aprendizagens de valores morais e sociais das crianças. Segundo Gomes, ${ }^{10: 240}$ esses valores são estabelecidos por pais e professores (figuras de autoridade), por meio de "conjuntos de valores e de códigos de conduta que devem ser transpostos para a relação educativa sob a forma de exemplos, de referência morais, que venham a ser interiorizadas pelos alunos".

Faz-se necessário, ainda, que a relação de respeito entre professores e alunos seja mútua e a de poder equilibrada, pois, segundo Aquino: $:^{11: 134}$ 
[...] toda relação institucionalizada, que se queira fecunda, não pode prescindir de algumas condições fundamentais quanto a seu funcionamento, as quais implicam desde o estabelecimento dos parâmetros de conduta para ambas as partes até, e principalmente, a explicitação contínua dos objetivos, limites e possibilidades da relação [...].

Logo, a postura que o professor assume perante seus alunos e o reconhecimento e a legitimação de sua própria autoridade são de suma importância para o desenvolvimento de um processo de ensino e de aprendizagem efetivo.

\section{TEORIA DOS ESTILOS PARENTAIS}

Segundo Darling e Steinberg, ${ }^{12: 488}$ os estilos parentais são um "conjunto de atitudes que são comunicadas à criança/jovem e que, todas juntas, criam um clima emocional, no qual os pais atuam de determinada forma". Muitos são os estudos sobre os estilos parentais e suas influências no desenvolvimento dos indivíduos.

A Teoria dos Estilos Parentais foi fundamentada por Diana Baumrind, em 1966. De acordo com essa teoria, os pais desenvolvem certos padrões de comportamento de controle sobre seus filhos, definidos em três modelos que podem ser percebidos como: estilo parental autoritário, estilo parental autoritativo/participativo e estilo parental permissivo.

Para Maccoby e Martin, ${ }^{13}$ uma melhor definição das condutas parentais levaria em consideração as dimensões da exigência e da responsividade. A dimensão da exigência corresponde às condições que a sociedade (família, escola, comunidade) impõe à criança como o cumprimento de regras, comportamento e ações nos ambientes sociais. A dimensão da responsividade refere-se às exigências da criança para com a sociedade - como carinho, atenção e suprimento de suas necessidades. Dessa forma, os autores propuseram a expansão do estilo parental permissivo em dois outros tipos: o estilo parental permissivo indulgente e o permissivo negligente, como se pode conferir abaixo. 
QUADRO 1 - Classificação dos estilos parentais sob a concepção das dimensões de responsividade e exigência

\begin{tabular}{|c|c|c|}
\hline \multicolumn{2}{|c|}{ DIMENSÕES } & \multirow{2}{*}{ ESTILO } \\
\cline { 1 - 2 } Responsividade & Exigência & Autoritativo \\
\hline Alta & Alta & Autoritário \\
\hline Baixa & Alta & Permissivo indulgente \\
\hline Alta & Baixa & Permissivo negligente \\
\hline Baixa & Baixa & \\
\hline
\end{tabular}

Fonte: MACCOBY; MARTIN. ${ }^{13}$

Como é possível observar, o estilo parental autoritativo (ou participativo), compreende pais que:

[...] solicitam suas objeções quando ela (a criança) se recusa a concordar; exercem firme controle nos pontos de divergência, colocando sua perspectiva de adulto, sem restringir a criança, reconhecendo que esta possui interesses próprios e maneiras particulares; não baseiam suas decisões em consensos ou no desejo da criança. ${ }^{5: 891}$

Esses pais incentivam a realização das atividades com demonstrações de afeto e satisfação e ajustam suas atitudes de acordo com as demandas de seus filhos e também de acordo com as especificidades de cada faixa etária.

O estilo parental autoritário é composto pelo conjunto de comportamentos e ações dos pais que visam "moldar, controlar e avaliar o comportamento e as atitudes da criança, de acordo com um padrão definido de conduta", $5: 890$ exercendo um firme controle sobre os filhos. As regras são colocadas como imposições absolutas, de forma que não há discussão com a criança sobre as consequências de seus atos. A desobediência da criança resulta em punição verbal e/ou física e as demonstrações de afeto e os estímulos positivos são raros.

O estilo parental permissivo compreende pais que não se apresentam como um modelo para as crianças, ou como norteadores de seu comportamento, mas apenas como um meio para a satisfação de seus desejos. Não há figura de comando além da própria criança. A criança regula suas atividades de acordo com sua própria vontade e os pais não conseguem incentivála a obedecer às regras definidas.

Estilo parental permissivo indulgente: nesse estilo estão os pais que são bastante responsivos, atendem as vontades da criança e frequentemente demonstram carinho, mas não exigem o cumprimento de normas e tarefas, não estimulando noções de responsabilidade e $\checkmark$ autonomia e tampouco servindo como modelo para a prole.

\begin{tabular}{|l|l|l|l|l|l|l}
\hline (C) Conexões & Campinas, SP & v. 14 & n. 1 & p. 66-86 & jan./mar. 2016 & ISSN 1983-9030 \\
\hline
\end{tabular}


Estilo parental permissivo negligente: nesse estilo se enquadram pais que não se empenham ou não se comprometem com suas funções parentais. Os pais são distantes e, com o passar do tempo, responsabilizam-se cada vez menos por seus filhos, correspondendo apenas às suas necessidades básicas (físicas, fisiológicas, intelectuais) a fim de esquivarem-se imediatamente das inconveniências. Esses pais não exigem o cumprimento de regras nem demonstram afeto.

\section{METODOLOGIA}

Trata-se de um estudo qualitativo sobre as posturas de professores de Educação Física do Ensino Fundamental Segundo Ciclo, de acordo com a tipologia da Teoria dos Estilos Parentais e as possíveis influências sobre o clima afetivo das aulas de Educação Física. O estudo foi aprovado pelo Comitê de Ética e Pesquisa da Unicamp, sob parecer número 30820814.3.0000.5404.

Utilizou-se como referência para organização e análise dos dados a adaptação do Questionário de Estilos e Dimensões Parentais (QEDP) - Versão Reduzida. ${ }^{14}$ Ressalta-se que a utilização da adaptação do questionário teve a função de apenas evidenciar a inclinação das posturas dos professores a determinado estilo de conduta. O questionário não foi aplicado a nenhum dos voluntários.

A caracterização das posturas dos voluntários da pesquisa se deu por meio de observação e registro das aulas em diário de campo, e posterior análise e comparação com as descritas no QEDP, identificando a predominância de determinado estilo nas práticas educativas dos voluntários. Dessa maneira, foram definidas três categorias de posturas educativas para os professores:

Estilo autoritativo: são professores que estão constantemente incentivando a participação dos alunos. São firmes no estabelecimento de regras e normas, mas também dão retorno afetivo aos estudantes. As regras e condições das aulas são claramente estabelecidas, mas não são fechadas. Suas aulas são mais dinâmicas, pois apresentam mais diversidade de conteúdo.

Estilo autoritário: se identificam os professores que não permitem e/ou não estimulam a participação dos alunos no processo de ensino-aprendizagem. Impõem regras e punem os alunos ou utilizam comunicação verbal rude quando desobedecidos. No caso da organização 
dos conteúdos da Educação Física, recorrem às aulas mais sistematizadas, como forma de controle sobre os alunos.

Estilo permissivo: são professores que quase nunca exigem o cumprimento de regras e quando o fazem, não são atendidos pelos alunos e podem dar ou não retorno afetivo a eles. Em geral, não planejam suas aulas e deixam que os alunos conduzam o conteúdo da aula como queiram.

\section{Local}

Foram escolhidas duas escolas localizadas na cidade de Campinas para o desenvolvimento do estudo. A primeira localiza-se na Vila Padre Anchieta e a segunda no Jardim Nova Aparecida, bairros do distrito de Nova Aparecida. Os critérios para a escolha das escolas foram a acessibilidade da pesquisadora às mesmas e a receptividade das instituições à pesquisa.

As escolas foram identificadas pelos números 1 e 2. Ambas as escolas são públicas, estaduais e possuem turmas de Ensino Médio e dos dois ciclos do Ensino Fundamental. Localizam-se nas proximidades do centro comercial do distrito de Nova Aparecida e possuem arredores bem estruturados em termos de saneamento básico, asfalto, atendimento médico e distribuição de energia. Atendem alunos não só do bairro onde se encontram, mas também de comunidades das redondezas. Em estudo sobre a região, Santos ${ }^{15}$ afirma que a renda dos habitantes dessa localidade é predominantemente média baixa e baixa.

As escolas se assemelham no tocante à arquitetura e disposição de suas dependências. No entanto, em relação à conservação e estrutura dos ambientes destinados à Educação Física, a escola número 1 fica muito aquém da escola número 2, pois as quadras e os materiais direcionados às atividades estão deteriorados, de forma a prejudicar as práticas.

\section{Participantes}

Foram solicitadas as participações de professores que lecionavam para alunos de $6^{\circ}$ ao $9^{\circ}$ ano. Ao todo, foram observadas as aulas de cinco professores, três da escola 1 e dois da escola 2. Foram escolhidos apenas os professores efetivos que tivessem pelo menos três anos de docência no Ensino Fundamental, não necessariamente na escola observada, para que se garantisse que já tivessem definidas suas práticas pedagógicas. Foi-lhes entregue, logo no

\begin{tabular}{|l|l|l|l|l|l|l}
\hline (C) Conexões & Campinas, SP & v. 14 & n. 1 & p. 66-86 & jan./mar. 2016 & ISSN 1983-9030
\end{tabular}


início das observações, o Termo de Consentimento Livre e Esclarecido (TCLE). Para identificar e melhor organizar os voluntários dessa pesquisa, foram divididos segundo a escola (números 1 e 2) e segundo a ordem de observação das aulas (A, B, C...). Dessa maneira, os participantes foram identificados como 1A, 1B, 1C, 2A e $2 \mathrm{~B}$.

Segue abaixo uma breve descrição dos voluntários.

QUADRO 2 - Descrição dos sujeitos

\begin{tabular}{|c|c|c|c|c|}
\hline Sujeito & Sexo & Idade & $\begin{array}{c}\text { Ano de formação } \\
\text { (graduação) }\end{array}$ & $\begin{array}{c}\text { Tempo como docente } \\
\text { na instituição }\end{array}$ \\
\hline 1A & Masculino & 42 anos & 1998 & 5 anos \\
\hline 1B & Masculino & $*$ & 2009 & 2 anos \\
\hline 1C & Feminino & 32 anos & 2006 & 2 anos \\
\hline 2A & Feminino & 28 anos & 2009 & 2 anos \\
\hline 2B & Masculino & 33 anos & 2004 & 4 anos \\
\hline
\end{tabular}

Legenda: * Idade não informada.

\section{Levantamento de informações}

A pesquisa baseou-se na observação participante das aulas que, segundo Vianna ${ }^{16}$, pode ser definida como uma forma de estudo no qual o pesquisador estabelece contato gradual com os indivíduos que compõem o espaço social e participa dos eventos que estão sendo pesquisados.

Para analisar os conteúdos registrados no diário de campo, utilizou-se o modelo analítico misto que corresponde à definição de categorias que o pesquisador espera encontrar em sua pesquisa. Porém, essas categorias são mutáveis: mudam de acordo com as características e necessidades da pesquisa ${ }^{17}$.

Foram observadas seis aulas de cinquenta minutos de cada professor, totalizando 300 minutos de aulas. Todas as aulas foram registradas em diário de campo que, segundo Minayo e Gomes, ${ }^{18}$ é uma das principais ferramentas em pesquisas que envolvam observações e análise qualitativa. Os registros do diário de campo foram manuscritos durante os momentos de aula e posteriormente digitalizados. Foram registradas, tanto quanto possível, as atividades, relações e conflitos entre professores e alunos. Porém, o foco principal das observações $\downarrow$ foram as posturas e as relações dos professores para com os alunos.

\begin{tabular}{l|l|l|l|l|l|l}
\hline (C) Conexões & Campinas, SP & v. 14 & n. 1 & p. 66-86 & jan./mar. 2016 & ISSN 1983-9030 \\
\hline
\end{tabular}




\section{RESULTADOS E DISCUSSÃO}

\section{Posturas educativas permissivas e autoritárias}

Por meio de análise do material registrado no diário de campo, constatou-se que os professores adotam diferentes posturas educativas que variam de acordo com as demandas de cada situação. Porém, mesmo havendo essa variação, os professores demonstraram certa inclinação para determinado estilo, que predominou sobre os outros.

Caracterizou-se o estilo permissivo entre os voluntários por meio dos comportamentos pouco efetivos no tocante à cobrança de regras e respeito à figura de autoridade que o professor representa (dimensão da exigência), acompanhados ou não por comportamentos afetivos (dimensão da responsividade).

Como primeiro exemplo, cita-se o registro do voluntário 2A:

“O tema da aula é 'capacidades físicas'. Depois de escrever na lousa as capacidades e explicar brevemente o que elas são, a professora sugere que os alunos joguem basquete e observem as capacidades utilizadas na modalidade. Os alunos (principalmente meninos) entram em alvoroço, argumentando que no futsal, atividade que desejavam realizar de fato, também é possível utilizar as capacidades. A professora cede ao pedido dos alunos e desce com eles para quadra. (Diário de Campo, $2^{\mathrm{a}}$ aula da professora $2 \mathrm{~A}$, turma de $8^{\circ}$ ano).

Já o voluntário 1B, numa aula de jogos competitivos de tênis de mesa, embora tenha expressado seu descontentamento, não conseguiu fazer com que os alunos o obedecessem:

"[...]O professor, com ajuda de alguns alunos, monta uma mesa de tênis de mesa (que está em estado ruim) e inicia jogos competitivos. Grita no pátio: 'Pessoal que vai participar, pode vir!' e alguns alunos se direcionam à mesa. A maioria dos outros alunos fica correndo, brincando com bambolês ou sentada, conversando. [...]Algumas meninas, numa brincadeira, atingem uma a outra com bambolês. Um dos bambolês se quebra e, vendo isso, o professor grita: 'Ô meninas! Não foi pra isso que deixei vocês brincarem com os bambolês!', e toma rispidamente um dos bambolês. As meninas, como se não tivessem ouvido nada, continuam correndo e se batendo com o bambolê que lhes resta, enquanto o professor retorna à mesa dos jogos." (Diário de Campo, $4^{\mathrm{a}}$ aula do professor $1 \mathrm{~B}$, turma de $8^{\circ}$ ano) 
Ambas as aulas nas quais foram registrados esses acontecimentos são semelhantes no relativo à dificuldade de o professor colocar-se numa posição de comando, que possa direcionar a aula, e à forma como é desenvolvido o conteúdo. As aulas, quando não totalmente livres, foram pouco direcionadas, de forma que os professores se colocavam mais como juízes das atividades e jogos do que como mediadores entre os alunos e o conhecimento. A caracterização dessas aulas se assemelha à definição de Darido e Sanches Neto ${ }^{19: 4}$ para o modelo de aula "rola-bola":

[...] assistimos ao desenvolvimento de um modelo no qual os alunos é que decidem o que vão fazer na aula, escolhendo o jogo e a forma como querem praticá-lo, e o papel do professor se restringe a oferecer uma bola e marcar o tempo. Praticamente, o professor não intervém.

Ainda na aula da voluntária 2A, tem-se o seguinte registro:

“[...] Segundo a professora, a maioria das atividades é negociada com os alunos, pois se fosse de outra forma, ela não conseguiria desenvolver os conteúdos." (Diário de Campo, $2^{\mathrm{a}}$ aula da professora $2 \mathrm{~A}$, turma de $8^{\circ}$ ano).

Porém, o que se pôde constatar durante as observações é que não houve uma negociação de fato. $\mathrm{Na}$ aula citada, os alunos se contrapuseram à proposta da professora e esta cedeu aos seus pedidos, sem maiores argumentações, para acabar com o alvoroço da turma.

$\mathrm{Na}$ análise das observações, as aulas se justificavam como "livres" por se enquadrar numa das seguintes situações:

- Não apresentavam nenhum conteúdo previamente planejado, de forma que os alunos é que escolhiam o que fariam ou;

- Apresentavam conteúdo geral, como no caso da aula de capacidades físicas da voluntária 2A, mas não apresentavam direcionamento por parte do professor, sendo que a aula possuía um tema, mas não um contexto de práticas e intervenções que se referissem a ele. 
Segundo Darido e Sanches Neto ${ }^{19: 4}$ “a prática de 'dar a bola' é bastante condenável, pois se desconsidera a importância dos procedimentos pedagógicos dos professores”. Além disso, a internalização do processo de aprendizado pelos alunos só é possível mediante um planejamento que vise objetivos a serem alcançados, em congruência com métodos, práticas e avaliações coerentes do ensino.

Se o professor dá liberdade para os alunos fazerem o que desejarem sempre, nega-se a ideia de aula, de conteúdo dirigido, de contraposição de saberes e de avanço no desenvolvimento de habilidades. E, por consequência, nega-se também a necessidade do professor, cuja função, além de tantas outras, é liderar, intermediar e direcionar a aula, a fim de cumprir objetivos estabelecidos em planejamento prévio.

Dentre vários motivos que embasam a adoção dessas condutas, os voluntários apontaram, em seus diálogos informais com a pesquisadora, a longa jornada de trabalho, a desvalorização da profissão e a deterioração das estruturas físicas e materiais das escolas como interferências em seu trabalho, assim como a desmotivação e falta de apoio oriundo da direção das escolas e do próprio sistema escolar.

\begin{abstract}
"A professora diz que muitas vezes se sentiu desmotivada a continuar dando aulas de qualidade para seus alunos. Segundo ela, falta apoio da direção e reconhecimento dos colegas de trabalho sobre a importância de sua área profissional. [...] Parte desse desânimo disse ser proveniente do sistema escolar, que desvaloriza e sucateia o ensino. Outra parte disse que procede dos alunos, que lhe faltam com respeito, aos quais nem sempre pode ajudar sem ter também o apoio da família e da comunidade extra e intra escolar." (Diário de Campo, $4^{\mathrm{a}}$ aula do sujeito $1 \mathrm{C}$, turma de $6^{\circ}$ ano)
\end{abstract}

Essa mesma voluntária diz já ter assumido, no início de sua experiência como docente, condutas mais impositivas aos alunos, como forma de tentar chamar-lhes a atenção, ser reconhecida e desenvolver as aulas segundo o planejamento. Porém, disse ser difícil distinguir a autoridade do autoritarismo e teve que, com o passar do tempo, ceder aos alunos para evitar conflitos:

A definição de Novais ${ }^{20: 21}$ de autoritarismo na sala de aula se assemelha à definição de Baumrind $^{4}$ para as condutas autoritárias parentais:

\begin{tabular}{|l|l|l|l|l|l|l}
\hline CCConexões & Campinas, SP & v. 14 & n. 1 & p. 66-86 & jan./mar. 2016 & ISSN 1983-9030 \\
\hline
\end{tabular}




\begin{abstract}
Sua característica principal é que os alunos, ao obedecerem, não o fazem por acreditar na autoridade docente, mas sim porque são obrigados, não têm escolha, ou seja, obedecem, mas não respeitam o professor, que se torna mais autoritário e utiliza mais instrumentos de coação, gerando mais indisciplina e consequentemente menos respeito por parte dos alunos. Neste sentido, a autoridade autoritária, decorrente de uma posição hierárquica, pode ser "aceita" simplesmente porque a lei ampara e não porque seu portador demonstra competência e autoridade.
\end{abstract}

Exemplificando a problemática autoridade versus autoritarismo, têm-se o seguinte acontecimento, que ocorreu numa aula teórica em sala:

“[...] Ele (o professor) então grita para chamar a atenção dos alunos. Diz que a partir da próxima aula, irá chamar três alunos por vez, para fazer uma avaliação oral sobre o conteúdo ensinado, para verificar se os alunos estão prestando atenção. [...] Vendo que os alunos estavam ainda em pé e conversando, ele diz para a turma que decidiu começar as avaliações orais naquele momento e chama uma aluna para começar. Um dos alunos, sentado próximo a mim, comenta com seu colega: 'Eu não vou responder nada, ele não pode me obrigar, ele não tem uma arma na minha cabeça..."” (Diário de Campo, $6^{\mathrm{a}}$ aula do professor $1 \mathrm{~A}$, turma de $7^{\circ}$ ano).

Percebe-se no ocorrido a tomada de uma atitude autoritária (avaliação como forma de punição) por parte do professor para tentar conseguir alguma atenção e respeito de seus alunos. Porém, assim como o sugerido por Novais, ${ }^{20}$ a ação apenas gerou mais indisciplina e menos respeito.

Assim como o participante 1A, todos os outros voluntários apresentaram algumas posturas autoritárias, no sentido de impor regras não internalizadas pelos alunos e que não eram seguidas pelos mesmos.

Por fim, foi possível perceber também a mudança de comportamento diante das diferentes salas. Todos os professores demonstraram mais ou menos afeto à determinada turma, o que influenciou também suas posturas. Como exemplo, têm-se os seguintes trechos do Diário de Campo:

"A caminho da sala, a professora me diz que essa é uma sala 'montada' pela direção da escola, com os melhores alunos dos oitavos anos. Diz que é uma sala muito boa de trabalhar, pois os alunos, embora falem bastante, são 'inteligentes'." (Diário de Campo, $5^{\mathrm{a}}$ aula da professora $2 \mathrm{~A}$, turma de $8^{\circ}$ ano) 


\begin{abstract}
"Antes de entrar na sala, o professor me diz que esta é uma turma de reforço, formada pela escola. É composta por alunos repetentes, com 'déficit de aprendizagem' ou sem diagnóstico. Diz que, por essa razão, tem que 'pegar mais leve' em relação ao conteúdo, senão a aula 'não rende'. A sala hoje tem apenas nove alunos, sendo que apenas um deles faltou à aula. [...] O professor passa a matéria, os alunos interagem pouco com o tema exposto e entre si. [...] Ao descerem para a quadra, os alunos não conseguem formar times para jogar e, dessa forma, alguns jogam jogos de tabuleiro, outros conversam em cantos da quadra. A turma está dispersa." (Diário de Campo, $2^{\mathrm{a}}$ aula do professor $2 \mathrm{~B}$, turma de $7^{\circ}$ ano).
\end{abstract}

Como se pôde perceber, havia mudanças na forma com que os professores lidavam com as diferentes turmas. Nos casos citados acima, essa situação ficou mais evidente porque a própria escola dividiu os alunos entre "alunos bons" e "alunos ruins". Sentia-se na sala de aula do segundo trecho acima, mais pessimismo e menos alegria, pois os alunos pouco falavam ou interagiam entre si. Os professores, em geral, demonstravam ainda menos esforço e preocupação com essas turmas.

\title{
Práticas educativas autoritativas
}

O ideal para identificação das posturas educativas autoritativas seria acompanhar os professores por mais tempo do que o disponível neste estudo. No entanto, mesmo com a pouca disponibilidade de observações, foi possível fazer algumas inferências sobre as práticas autoritativas.

O participante $2 \mathrm{~B}$, por exemplo, apresentou posturas autoritativas no que concerne ao equilíbrio entre responsividade e exigência. $O$ professor se demonstrou firme quanto ao estabelecimento de regras, porém, as contextualizava aos alunos. Além disso, permitiu em alguns momentos, que os alunos expressassem seus pensamentos e sentimentos frente aquilo que lhes era colocado, dando abertura para modificações. Como exemplo, tem-se o seguinte trecho do diário de campo, que relata uma aula na qual o professor conversa com seus alunos sobre a premiação de uma competição que havia ocorrido na escola:

"O professor começa a explicar como seria feita a entrega das medalhas da competição de futsal que ocorreu baseada na Copa do Mundo de Futebol. O professor diz à turma que as medalhas seriam entregues às salas dos três primeiros times colocados. Alguns alunos argumentam e uma menina diz que o certo seria que as medalhas 
fossem entregues a todos, já que todos participaram de alguma maneira, na torcida, confeccionando cartazes etc. O professor então pergunta para a turma como eles achavam que deveria ser o critério de entrega de medalhas. Todos falam ao mesmo tempo. Um dos meninos diz que o professor não deveria entregar para quem não fez nada, já que seria injusto com aqueles que participaram. Uma menina diz que não fez nada porque gostaria de ter participado dos jogos, mas não sabia jogar futsal.

O professor ouve os alunos e diz que, para não ser injusto com ninguém, iria entregar medalhas de participação a todos e que, na próxima competição, adotaria um esquema de pontuação que contasse também a participação da sala e não apenas os resultados dos jogos. Lembrou os alunos de que a participação nos eventos também é obrigatória e é tão importante quanto a participação nas aulas, pois faz parte do conteúdo da disciplina." (Diário de Campo, $4^{\mathrm{a}}$ aula do professor $2 \mathrm{~B}$, turma de $6^{\mathrm{o}}$ ano).

No relato acima, o professor conseguiu expressar seu ponto de vista, assim como seus alunos. O professor pôde expor certo controle sobre as regras, mas sem perder o envolvimento da turma, mantendo um clima afetivo e compreensivo para com os seus alunos. Sentia-se, naquela turma, maior abertura dos alunos para dizer o que pensavam sem recorrer a insultos ou desrespeito ao professor. Da mesma maneira, o professor conseguia desenvolver melhor as atividades, pois havia um clima de colaboração coletiva.

Segundo Weber ${ }^{21: 76}$ as posições de responsividade e exigência:

[...] caminham juntas nos pais autoritativos, os quais representam o estilo ideal de educação justamente por conseguir equilibrar controle e envolvimento. Quando os pais fazem exigências e compreendem o lado dos filhos, ensinam da melhor forma quais são as regras e limites para se obter sucesso, explicando os porquês. Esse clima gerado pela combinação da responsividade com a exigência dos pais só pode ser favorável ao otimismo na criança, pois ela aprende que tem capacidade para sozinha lidar com sucessos e frustrações, que pode fazer novas tentativas e obter melhores resultados.

Pode-se concluir que da mesma forma essas posições ocorram com professores autoritativos. Quando o professor tem controle sobre as regras e sobre como e quando colocá-las e, ao mesmo tempo, dá oportunidade de expressão aos seus alunos, ouvindo e conciliando suas opiniões, cria-se um clima de relação bidirecional, na qual há respeito e sentimento de pertencimento ao grupo escolar. Para se entender melhor os motivos que fazem um professor ser mais autoritativo, se fazem necessárias pesquisas futuras que evidenciem a história de vida do professor, sua formação pessoal e profissional, seu ambiente de trabalho e o contexto

\begin{tabular}{|l|c|c|c|c|c|c|}
\hline CC Conexões & Campinas, SP & v. 14 & n. 1 & p. 66-86 & jan./mar. 2016 & ISSN 1983-9030
\end{tabular}


sociocultural no qual está inserido. Essa forma de proceder foi menos comum entre o grupo estudado, o que revela que as posturas anteriormente mencionadas ainda são as mais frequentes entre os professores investigados.

\section{CONSIDERAÇÕES FINAIS}

Inicialmente, supôs-se que os professores que pouco intervissem na aula, assumiriam uma postura mais permissiva. Diante das observações das aulas e da composição do estudo, essa suposição foi confirmada. Todos os professores se mostraram, na maior parte do tempo, mais permissivos do que autoritativos ou autoritários.

Assumindo a instituição escolar sob a perspectiva de Dayrell, ${ }^{22}$ como um espaço sociocultural, onde os agentes que o compõem trazem consigo influências de outros âmbitos da vida e, com isso, o modificam e o significam, pode-se supor que a adoção das condutas permissivas por parte dos docentes pode não ser de sua exclusiva responsabilidade, pois o Estado, a família e a própria comunidade também têm obrigações para com a escola. Quando essas instituições sociais se eximem de suas responsabilidades e sobrecarregam o docente, há de se esperar que o ensino não seja de melhor qualidade. Deste modo, segundo o relato obtido, a adoção de práticas permissivas por parte dos professores dessa pesquisa deve-se, em grande parte, à desvalorização da profissão, somada às desfavoráveis condições de trabalho, como pagamentos, carga horária, estruturas físicas e apoio institucional.

Confirmou-se que as posturas docentes foram majoritariamente permissivas também por não possuírem planejamento ou grande envolvimento com os conteúdos tratados e que isso desmotivava os alunos, que respondiam desrespeitando o professor ou simplesmente não participando das aulas. Constatou-se também que, ao cobrar uma regra ou um comportamento de seu aluno, o professor deve ter equilíbrio entre as dimensões de responsividade e exigência. Esse equilíbrio, somado a ações pedagógicas consistentes que considerem as necessidades e realidades do aluno e um planejamento coerente, formam a figura de autoridade da qual o professor disporá para tornar legítimas suas práticas e sua posição sóciohistórica na sala de aula. 
Esse estudo, porém, não basta para compreender toda a complexa díade professor-aluno. Sabe-se que as posturas dos professores têm efeito sobre o comportamento dos alunos, mas que parte caberia ao aluno nessa relação? Ademais, realizar entrevistas para documentar os diferentes pontos de vista e estudar a história de vida de cada voluntário enriqueceria a discussão.

De todo modo, essa pesquisa pôde trazer mais informações sobre o cotidiano escolar, sob a perspectiva dos estilos educativos dos professores, contribuindo para o melhor entendimento sobre os fatores que influenciam os comportamentos dos alunos e sobre as relações entre eles e seus professores.

Essa relação é marcante, pois não se trata apenas de interação entre pessoas, mas também da interação entre valores, significados, interesses, sentimentos. O professor, por ocupar um espaço de autoridade, tem responsabilidades sobre aqueles aos quais guia, pois, assim como no ambiente familiar, servirá como exemplo, como modelo de conduta, pois influenciará diretamente o desenvolvimento acadêmico, social, comportamental e psicológico de seus alunos. Desse modo, há que se refletir sobre a condição de docente que, por tantas vezes, é desvalorizada e menosprezada não apenas pela sociedade, mas pelos próprios professores.

\section{REFERÊNCIAS}

${ }^{1}$ DESSEN, Maria Auxiliadora; POLONIA, Ana da Costa. A família e a escola como contextos de desenvolvimento humano. Paidéia, v. 17, p. 21-32, 2007. Disponível em: <http://www.scielo.br/scielo.php?script=sci_arttext\&pid=S0103-863X2007000100003>. Acesso em: jul. 2014.

${ }^{2}$ CUNHA, Maria Isabel. O bom professor e a sua prática. Campinas: Papirus, 1989.

${ }^{3}$ KUNZ, Elenor. Transformação didático-pedagógica do esporte. Ijuí: Ed. da Unijuí, 1994.

${ }^{4}$ CHARLOT, Bernard. Da relação com o saber, elementos para uma teoria. Porto Alegre: Artmed, 2000. 
${ }^{5}$ BAUMRIND, Diana. Effects of authoritative parental control on child behavior. Child Development, n. 37, p. 323/890, 1966. Disponível em:

<http://arowe.pbworks.com/f/baumrind_1966_parenting.pdf> Acesso em: ago.2013.

${ }^{6}$ SENNETT, Richard. Autoridade. Rio de Janeiro: Record, 2001.

${ }^{7}$ BOURDIEU, Pierre. O poder simbólico. Rio de Janeiro: DIFEL, 1989.

${ }^{8}$ ARENDT, Hannah. Entre o passado e o futuro. São Paulo: Perspectiva, 1997.

${ }^{9}$ ARENDT, Hannah. A condição humana. 10. ed. Rio de Janeiro: Forense Universitária, 2007.

${ }^{10}$ GOMES, Carlos Alberto. Poder, autoridade e liderança institucional na escola e na sala de aula: perspectivas sociológicas clássicas. Ensaio: avaliação e políticas públicas em educação, Rio de Janeiro, v. 17, n. 63, abr./jun. 2009. Disponível em: <http://www.scielo.br/scielo.php?script=sci_arttext\&pid=S0104-40362009000200004>. Acesso em: set. 2014.

${ }^{11}$ AQUINO, J. R. G. Autoridade docente, autonomia discente: uma equação possível e necessária. In: Autoridade e autonomia na escola: alternativas teóricas e práticas. São Paulo: Summus, 1999.

${ }^{12}$ DARLING, Nancy; STEINBERG, Laurence. Parenting style as context: an integrative model. Psychological Bulletin, v. 113, 1993. Disponível em:

<http://www.oberlin.edu/faculty/ndarling/lab/psychbull.pdf >. Acesso em: set. 2013.

${ }^{13}$ MACCOBY, E.; MARTÍN, J. Socialization in the context of the family: parent-child interaction. In: MUSSEN, P. H.; HETHERINGTON, E. M. (Org.). Handbook of child psychology: socialization, personality and social development. 4. ed. New York: Wiley, 1983. p. 1-101. 
${ }^{14}$ MIGUEL, Isabel; VALENTIM, Joaquim Pires; CARUGATI, Felipe. Questionário de estilos e dimensões parentais - versão reduzida: adaptação portuguesa do parenting stylesand dimensions questionnaire - short form. Revista Psychologica, Coimbra, v. 51, p. 169-188, 2009. Disponível em: <http://iduc.uc.pt/index.php/psychologica/article/view/1021>. Acesso em: set. 2013.

${ }^{15}$ SANTOS, João Henrique dos. Moradia popular em Campinas: um estudo do Conjunto Habitacional Edivaldo Antônio Orsi. 2008. Trabalho de Conclusão de Curso (Graduação) Centro de Ciências Exatas, Ambientais e de Tecnologias, Pontifícia Universidade Católica de Campinas, Campinas, 2008. Disponível em:

<http://www.educadores.diaadia.pr.gov.br/arquivos/File/2010/artigos_teses/GEOGRAFIA/M onografias/moradia_popular_campinas.pdf>. Acesso em: set. 2014.

${ }^{16}$ VIANNA, H. M. Pesquisa em educação: a observação. Brasília: Liber Livro, 2007.

${ }^{17}$ LAVILLE, Christian; DIONNE, Jean. A construção do saber: manual de metodologia de pesquisa em ciências humanas. Porto Alegre: Artmed; Belo Horizonte: Editora daUFMG, 1999.

${ }^{18}$ MINAYO, Maria Cecília de Souza (Org.). Pesquisa social: teoria, método e criatividade. 28. ed. Petrópolis: Vozes, 2009.

${ }^{19}$ DARIDO, Suraya Cristina; SANCHES NETO, Luiz. O contexto da educação física na escola. In: DARIDO, Suraya Cristina; RANGEL, Irene Conceição Andrade (Org.).

Educação Física na escola: implicações para a prática pedagógica. 2. ed. Rio de Janeiro: Guanabara Koogan, 2011.

${ }^{20}$ NOVAIS, Elaine Lopes. É possível ter autoridade em sala de aula sem ser autoritário? Linguagem \& Ensino, v. 7, n. 1, 2004. Disponível em:

<http://www.rle.ucpel.tche.br/index.php/rle/article/view/213>. Acesso em: fev. 2014.

${ }^{21}$ WEBER, Lidia Natalia Dobrianskyj; BRANDENBURG, Olivia Justen; VIEZZER, Ana Paula. A relação entre o estilo parental e o otimismo da criança. Psico-USF, v. 8, n. 1, 
jan./jun. 2003. Disponível em: < http://www.scielo.br/pdf/pusf/v8n1/v8n1a10>. Acesso em: abr. 2013.

${ }^{22}$ DAYRELL, Juarez. A escola como espaço sócio-cultural. In: DAYRELL, J. (Org.).

Múltiplos olhares sobre educação e cultura. Belo Horizonte: Ed. da UFMG, 1996. p. 136 161. 